\title{
Getting to grips with the beast: the potential of multi-method operational research approaches
}

\section{Jenni Burt}

Correspondence to Jenni Burt, General Practice and Primary Care Research Unit, University of Cambridge, Cambridge, CB2 OSR UK; jab35@medschl.cam.ac.uk

Accepted 9 January 2017 Published Online First 30 January 2017

\section{SLinked}

http://dx.doi.org/10.1136/ bmjqs-2016-005636

CrossMark

To cite: Burt J. BMJ Qual Saf 2017;26:611-612.
Many of us will be familiar with the parable of the blind men and the elephant, beautifully retold by the 19th century American poet John Godfrey Saxe. ${ }^{1}$ In this tale, each man in turn describes the small part of the elephant they are touching (the flank, the tusk, the trunk, etc.), declaring with confidence that they know the true nature of the object ('It's a wall!', 'A spear!', 'A snake!'). Saxe ends with the moral of the tale:

\section{So, oft in theologic wars \\ The disputants, I ween, \\ Rail on in utter ignorance \\ Of what each other mean; \\ And prate about an Elephant \\ Not one of them has seen! ${ }^{1}$}

This seems to be a fair summary of where we still too frequently find ourselves in health services research and delivery. Though the rise of extensive, multi-method programmes of work evaluating complex, multi-stranded services is a prominent feature of recent years, we often remain uncertain about the true nature of the beast we have been studying, and challenged by how we might tame or improve it. A key strength of collaborative research programmes is their ability to generate multiple understandings and perspectives; however, we frequently risk finishing, at the end of many years of enquiry, with a collection of exquisitely rendered drawings of various bits of an elephant, with no way of assembling them into something that might function effectively out in the wild.

In this edition of the journal, Crowe et $a l^{2}$ explore the potential for multimethod operational research approaches to take empirical research findings into the development of concrete service improvement recommendations for a complex care pathway (in this case, for infants with congenital heart disease, where care involves multiple providers, from tertiary to community settings). Crucially, there is a specific acknowledgement of the need to draw upon the multiple stakeholder perspectives located within the care delivery system to derive a solution to identified problems that 'everyone can live with'.

The approach draws on a set of principles adapted from Soft Systems Methodology, using iterative methods to understand the situation and problem, build conceptual models, use these models to explore the situation from multiple perspectives and generate potential actions for change. ${ }^{3}$ To achieve this, considerable research work had already taken place-a systematic literature review, ${ }^{4}$ analyses of routine data, ${ }^{5}$ interviews with parents and healthcare professionals $^{6-8}$ and facilitation of an online parent discussion forum. In most research programmes, this is where we typically stop-though knowledge exchange approaches can mean we are getting a little more creative and ambitious in how we get our findings 'out there'. Disseminating new research findings is a far cry, however, from actively integrating and using them to shape change, and here is where multi-method operational research may offer a useful approach which will be new to many.

As with any unfamiliar field, the jargon may seem off-putting at first. In Soft Systems Methodology, existing empirical data are used to inform Root Definitions, Activity Diagrams and 'Rich Pictures' (a term destined to make my quantitative colleagues shudder). However, the basic core of this approach is very sensible: a guided series of steps to move from 
research to action. Those steps include integration of research findings; presentation of these in multiple ways to summarise different perspectives; flagging of areas for potential improvement and, finally, collaboration with interested parties to develop and gain consensus on suggested service improvements. To anyone who undertakes evaluations of care to actually improve that care, the demonstration that this approach has utility not just in single organisational settings, where it has been predominantly applied to date, but across complex, multi-sector services, is good news.

Inevitably, questions remain unanswered. The authors acknowledge that their measured impact was solely on the initial development of recommendations for service improvement. Implementation scientists will be wise to the jungle that nascent evidence-based recommendations must negotiate to successfully drive and sustain changes in care. ${ }^{10} \mathrm{~A}$ key area for future work is therefore in understanding the necessary conditions required for the products of operational research approaches to survive, and thrive, on their own as they are taken forward from the safety of the research programme. Further, we need greater understanding of the resources (time, skills and funding) required to implement operational research approaches from the beginning of research programmes.

In the mixed methods research community, the work required to undertake an integrative analysis of separate datasets (already appropriately and separately analysed using traditional analytical approaches) is commonly known as the 'third effort'-and it's the bit that always happens as a race against time at the end, or frequently after the end, of the project. ${ }^{11}$ Certainly, in the current study, the labour required to generate the Rich Pictures and Activity Diagrams, and convene the working group, must have been considerable. New programmes would be wise to consider carefully how these can be formulated, planned and resourced as a core part of their activities.

These concerns are likely to be tractable. What is exciting is the potential in the application of operational research approaches, particularly those integrating quantitative and qualitative techniques, to help generate an accurate picture of the whole elephant-and to refine and prime the elephant for life in the healthcare jungle.

Competing interests None declared.

Provenance and peer review Commissioned; internally peer reviewed.

\section{REFERENCES}

1 Saxe JG. The blind men and the elephant. http://www. poemhunter.com/poem/the-blind-man-and-the-elephant/ (accessed 23 Dec 2016).

2 Crowe S, Brown K, Tregay J, et al. Combining qualitative and quantitative operational research methods to inform quality improvement in pathways that span multiple settings. BMJ Qual Saf 2017;27:641-52.

3 Checkland P. Soft systems methodology: a thirty year retrospective. Syst Res Behav Sci 2000;17:S11.

4 Tregay J, Wray J, Bull C, et al. Unexpected deaths and unplanned re-admissions in infants discharged home after cardiac surgery: a systematic review of potential risk factors. Cardiol Young 2015;25:839-52.

5 Crowe S, Ridout DA, Knowles R, et al. Death and emergency readmission of infants discharged after interventions for congenital heart disease: a national study of 7643 infants to inform service improvement. J Am Heart Assoc 2016;5:e003369.

6 Tregay J, Wray J, Crowe S, et al. Going home after infant cardiac surgery: a UK qualitative study. Arch Dis Child 2016;101:320-5.

7 Tregay J, Brown KL, Crowe S, et al. Signs of deterioration in infants discharged home following congenital heart surgery in the first year of life: a qualitative study. Arch Dis Child 2016;101:902-8.

8 Tregay J, Brown K, Crowe S, et al. 'I was so worried about every drop of milk'-feeding problems at home are a significant concern for parents after major heart surgery in infancy. Matern Child Nutr Published Online First: 19 February 2016.

9 Bielak AT, Shaxson L, Clappison A, et al. Expanding our understanding of $\mathrm{K}^{*}$ (KT, KE, KTT, KMb, KB, KM, etc.): a concept paper emerging from the $\mathrm{K}^{*}$ conference held in Hamilton, Ontario, Canada, April 2012. Published by United Nations University, Institute for Water, Environment and Health. Hamilton, Canada. http://inweh.unu.edu/wp-content/ uploads/2012/01/KStar_ConceptPaper_FINALWEB.pdf. (access date 25 Jan 17 2012).

10 Marshall MN. Bridging the ivory towers and the swampy lowlands; increasing the impact of health services research on quality improvement. Int J Qual Health Care J Int Soc Qual Health Care 2014;26:1-5.

11 Morgan DL. Practical strategies for combining qualitative and quantitative methods: applications to health research. Qual Health Res 1998;8:362-76. 